\title{
Comparison of screening strategies for prevalent vertebral fractures in South Korea: vertebral fracture assessment vs. spine radiography
}

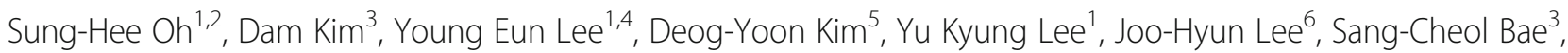
Yun Young Choi ${ }^{7}$, Junhee Pyo ${ }^{8}$, Jeonghoon Ahn ${ }^{1,9^{*}}$ and Yoon-Kyoung Sung ${ }^{3^{*}}$

\begin{abstract}
Background: Vertebral Fracture Assessment (VFA) is a useful tool to detect the vertebral fracture (VF) with low cost and radiation exposure. We aimed to compare screening strategies including VFA and spine radiography (X-ray) for detecting VF in terms of clinical effectiveness, cost and radiation exposure.

Methods: Three screening strategies: 1) X-ray following VFA, 2) VFA only, and 3) X-ray only were compared using a Markov model based on administrative data from South Korea in a population aged $\geq 50$ years. We compared the incidence of new VFs, cost-effectiveness of reducing new VFs and radiation exposure in each strategy.

Results: The incidence of new VFs was reduced in all screening strategies compared to no screening: 29.4\% for women and $12.5 \%$ for men in both X-ray following the VFA and VFA only strategies and 35\% for women and 17. $5 \%$ for men in the X-ray only strategy. The X-ray following VFA strategy had the lowest cost, followed by the X-ray only, and VFA only strategies. The radiation doses for X-ray only were 2,647-2,989 $\mu$ SV and 3,253-3,398 $\mu$ Sv higher than in the X-ray following VFA and VFA only strategies. The new VF prevention effect was greater in women, and more prominent in older people (women $\geq 70$, men $\geq 80$ ) than people $\geq 50$ years.
\end{abstract}

Conclusions: The X-ray following VFA strategy is a cost-effective option for screening prevalent VF to prevent new $V F$ in people aged $\geq 50$ years due to its high effectiveness, lowest cost, and least radiation exposure.

Keywords: Spinal fracture, Radiography, Diagnostic imaging, Cost effectiveness, Radiation

\section{Background}

Vertebral fracture (VF) is the most common sign of osteoporosis and indicates a higher risk of subsequent VFs $[1,2]$. According to previous literature, only around one-fourth to one-third of prevalent VFs are recognized clinically [3-5]. However, detection of prevalent VFs is important because

\footnotetext{
* Correspondence: ahnjeonghoon@ewha.ac.kr; sungyk@hanyang.ac.kr Sung-Hee Oh and Dam Kim contributed equally to this work and are joint first authors.

Jeonghoon Ahn and Yoon-Kyoung Sung contributed equally to this work and are joint corresponding authors.

${ }^{1}$ National Evidence-based Healthcare Collaborating Agency, Seoul, Republic of Korea

${ }^{3}$ Department of Rheumatology, Hanyang University Hospital for Rheumatic Diseases, 222-1 wangsimni-ro, Seoundong-gu, Seoul 133-792, Republic of Korea

Full list of author information is available at the end of the article
}

new VFs can be prevented by starting osteoporosis medication at the time of detection, even though bone mineral density (BMD) is not low [5-8]. In clinical practice, screening of VFs is rarely performed because of its cost, fear about radiation exposure, and inconvenience.

Spine radiography (X-ray) and vertebral fracture assessment (VFA) by dual energy X-ray absorptiometry (DXA) can readily detect prevalent VFs [9]. Until now, lateral thoracic and lumbar X-rays have been used as the gold standard for VF identification [6], because of the potential false negative rate of VF due to the poor image quality of the upper thoracic vertebrae in VFA $[10,11]$. However, VFA has recently been considered as a practical and reliable diagnostic tool with a lower radiation dose of 2-50 $\mu \mathrm{Sv}$ compared to $600 \mu \mathrm{Sv}$ for X-rays [12] and 
provides greater convenience in assessing VFs at the same time as measurement of BMD [5].

Increasing evidence indicates that the sensitivity and specificity of VFA are as high as those of X-ray with lower cost and radiation exposure [13]. There has been one study of the cost-effectiveness of VFA versus X-ray in postmenopausal women with osteopenia [14] but none assessing the clinical benefits and disadvantages of X-ray and VFA as a screening tool in the general population. Therefore, in this study, we aimed to compare the clinical effectiveness, costeffectiveness, and radiation exposures of VF screening strategies in adults aged 50 years and older using X-ray following VFA, VFA only and X-ray only as performed to detect prevalent VFs early and to prevent new VFs.

\section{Methods}

\section{Model overview}

A model structure comparing the screening strategies for prevalent VFs was developed from a review of the literature [15], clinical guidelines [9, 16], and expert opinion. A Markov model using a cohort simulation with each cohort of 1000 samples for women and men aged 50 years and older that compared screening strategies for identifying the presence of both asymptomatic and symptomatic VFs was created. We ran three Markov models simultaneously, one for each of the screening strategies for detecting prevalent VFs: 1) X-ray following VFA, which is screening of VFA followed by X-ray as confirmation test in patients who were suspicious of vertebral fracture, 2) VFA only, and 3) X-ray only. This index strategy of screening was compared to not doing any screening strategy before recognition of a new VF (No screening) (Fig. 1a).

The health states used in the Markov model were No VF, Prevalent VF, Post VF, New VF, and VFA impossible. Prevalent VF included radiographic VFs diagnosed by $\mathrm{X}$-ray as well as symptomatic VFs. The subjects started at an initial state of No VF or Prevalent VF. We assumed that the patients with a VF could not move back to the No VF state. All patientswho tested positive for VF were assumed to receive anti-osteoporotic therapy for one year, and patients who tested negative for VF were

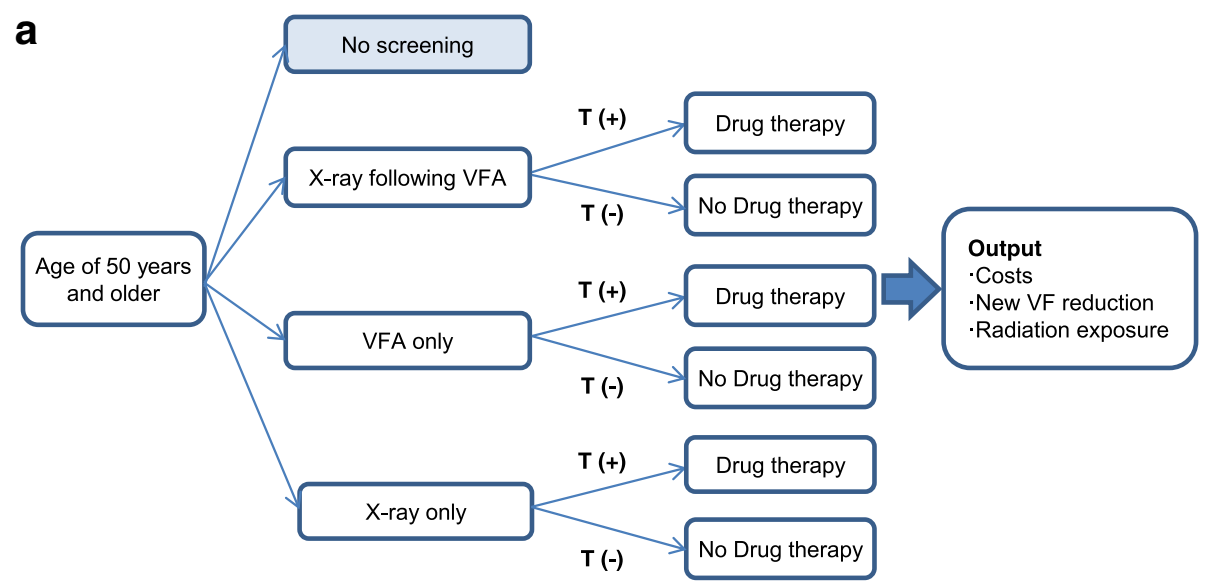

b

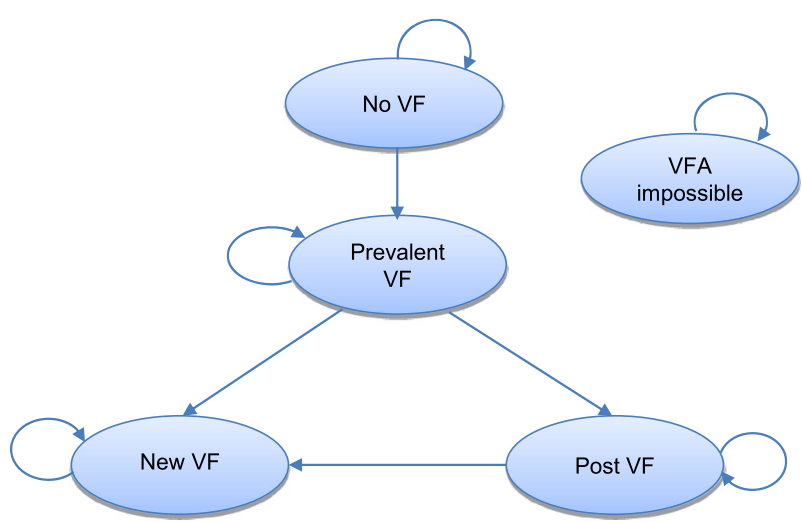

Fig. 1 Model structure for screening strategies to identify prevalent VF. T, test; VF, vertebral fracture; VFA, vertebral fracture assessment; (+), positive; (-), negative. a Simplified decision tree: Subjects who tested positive for prevalent VF were treated with anti-osteoporotic drugs, and the cycle length of the screening test was two years. b State transition diagram: the Markov model had five health states: No VF, Prevalent VF, Post VF, New VF, and VFA impossible. If the diagnosis of the new VF has been made once, patients with drug therapy are ruled out of the simulation targets 
assumed not to receive anti-osteoporotic therapy. They could either remain in the present state or transit to Post $V F$ or New VF in a subsequent cycle depending on the effect of drug therapy. Throughout the 10-year period, each subject was allowed to experience a new VF after the first VF. Once diagnosis of a new VF was made, a patient on drug therapy was excluded from the simulation. The model also considered VFA impossible as the absorbing state, which means that the VFA was unreadable as a result of poor image quality (Fig. 1b) [11].

\section{Probability data and key assumptions}

The prevalence of VFs in adults aged 50 years and older was obtained from a large-scale cohort study conducted in South Korea $[17,18]$. The incidence of VFs was estimated based on the linked data between a hospital cohort and the National Health Insurance (NHI) claims database of South Korea [19]. Moreover, the adjusted value was multiplied by an asymptomatic to symptomatic VF ratio of 2.8, which was the weighted average calculated by the literature $[4,20,21]$. This was used because the incidence of VFs before adjustment only considers patients who are clinically diagnosed VFs (Table 1).

In regard to diagnostic accuracy of VFA, the sensitivity and specificity VFA per-patient were taken from a published systematic review and report [13, 22]. In addition, we calculated the unreadable vertebrae on the VFA as 0.03 (95\% CI, 0.04-0.17) per patient and 0.05 (95\% CI, 0.04-0.08) per vertebra using random-effect estimates [22]. We assumed that the X-ray has a sensitivity and specificity of 1.00 as the gold standard (Table 1).

The relative risk (RR) for new VFs was derived from five systematic review studies [19, 23-26]. The pooled $R R$ was calculated by averaging the RRs weighted by the market share of the prescribed drug based on the 2012 claims database by health insurance review and assessment service (HIRA) (Table 1). We assumed that patients with diagnosed VFs will receive pharmacotherapy for a one year treatment period according to a previous trial [7] and expert opinions. However, the model did not consider the likelihood of adverse drug reaction

Table 1 Summary of the input parameters in the model for base case analysis and univariate sensitivity analysis

\begin{tabular}{|c|c|c|c|c|}
\hline \multirow[t]{2}{*}{ Parameter } & \multicolumn{2}{|l|}{ Value $^{a}$} & \multirow[t]{2}{*}{ Sources } & \multirow[t]{2}{*}{ Note } \\
\hline & Women & Men & & \\
\hline \multicolumn{5}{|l|}{ Probabilities } \\
\hline VF prevalence & $0.22[0.08]$ & $0.11[0.03]$ & HIRA, $[17,18]$ & NHI database [Community-based cohort] \\
\hline two-year VF incidence & $0.12[0.13]$ & $0.05[0.05]$ & HIRA, [32] & NHI database [Community-based cohort] \\
\hline two-year new VF incidence & $0.22[0.23]$ & $0.22[0.23]$ & {$[19,32]$} & Hospital cohort- NHI database linked data [Community-based cohort] \\
\hline RR of new VF on drug therapy & $0.58[0.64]$ & $0.38[0.41]$ & {$[19,23-26]$} & Meta-analysis literature review, pooled RR [decrease by 10\%] \\
\hline \multicolumn{5}{|l|}{ Diagnostic accuracy } \\
\hline Sensitivity of X-ray & 1.00 & 1.00 & & Gold standard \\
\hline Specificity of X-ray & 1.00 & 1.00 & & Gold standard \\
\hline Sensitivity of VFA & $0.82[0.74]$ & $0.82[0.74]$ & {$[22]$} & SR [95\% CI lower limit, conservative] \\
\hline Specificity of VFA & $0.93[0.89]$ & $0.93[0.89]$ & {$[22]$} & SR [95\% Cl lower limit, conservative] \\
\hline VFA impossible & $0.03[0.05]$ & $0.03[0.05]$ & {$[22]$} & SR, per patient [per vertebrae] \\
\hline \multicolumn{5}{|l|}{ Costs $(€)^{b}$} \\
\hline VFAc & $17[40]$ & $17[40]$ & {$[27]$} & $50 \%$ of $X$-ray test costs [Increase by $200 \%$ of $X$-ray costs, conservative] \\
\hline X-ray ${ }^{c}$ & $24[17]$ & $24[17]$ & HIRA & EDI code, thoracic and lumbar spine in the AP and lateral \\
\hline VFs treatment & $1526[1249]$ & $1707[1336]$ & HIRA & NHI database, per patient [Mild VF relatively] \\
\hline Physician visits & 9 & 9 & HIRA & NHI database, per visit \\
\hline Drug therapy & 180 & 194 & HIRA & Drug weighted average charge, one-year administration \\
\hline Procedure & 809 & 934 & HIRA & NHI database, only in symptomatic VF cases \\
\hline \multicolumn{5}{|l|}{ Radiation doses ( $\mu S v)$} \\
\hline X-ray & 600 & 600 & {$[12]$} & \\
\hline VFA & $25[2]$ & $25[2]$ & [12] & Average level of 2 to $50 \mu \mathrm{Sv}$ [lower limit] \\
\hline
\end{tabular}

VF vertebral fracture, HIRA Health Insurance Review and Assessment Service, NHI National Health Insurance, $R R$ relative risk, $A P$ anterior-posterior, VFA vertebral fracture assessment, $S R$ systematic review

${ }^{a}$ Value in brackets, []: Inputs data for univariate sensitivity analysis

${ }^{b}$ Korean won converted to euros $(€)$ using an exchange rate of $1 €=1482$ KRW (2013)

'VFA and X-ray costs included the test and a physician visit 
from unnecessary treatment with a false-positive VFA image.

\section{Cost and radiation exposure data}

Cost data were collected from the NHI claims data from the HIRA in South Korea [22]. The unit costs for two categories, screening tests and VF treatment, are presented in Table 1. When estimating the costs of the index tests, $\mathrm{X}$-ray was defined as using standard radiographic techniques for VF identification [6]. Since we do not have determined cost of VFA, we calculated that VFA imaging would cost half that of the X-ray, reflecting the U.S. relative cost [27]. The treatment cost of VFs included medical costs such as physician visits, drug therapy, or related procedures. A discount rate of $5 \%$ was applied to the future costs with half-cycle corrections according to the South Korean economic evaluation guidelines [28]. All costs were estimated in year 2013 euros using the health care component of the Consumer Price Index [29] and the exchange rate $(1 €=1482 \mathrm{KRW}$ in 2013).

We applied the exposure to radiation at every cycle length of the test at $600 \mu \mathrm{Sv}$ for X-ray; $25 \mu \mathrm{Sv}$ - middle level of the reported range $(2-50 \mu \mathrm{Sv})$-for VFA; and $625 \mu \mathrm{Sv}$ for X-ray following VFA, respectively [12]. The strategy of no screening was assumed to have no significant exposure to radiation.

\section{Statistical analysis}

In the base case analysis, we compared the clinical benefits and harm of doing the screening strategies (defined as Do screening, which presents the average expected values of the X-ray following VFA, VFA only, and X-ray only strategies) every two years and No screening. The outcome measures included incidence of new VFs (\%), costs of tests and VFs treatment $(€)$, and radiation exposure $(\mu \mathrm{Sv})$ of the three screening strategies compared to the No screening strategy. Consequently, the results were calculated as follows.

Incremental effectiveness $(\Delta \mathrm{E})$

$$
=\text { Effect }_{\text {index test }}-\text { Effect }_{\text {no screening }}(\%)
$$

Incremental costs $(\Delta C)$

$$
=\text { Costs }_{\text {index test }}-\text { Costs }_{\text {no screening }}(€)
$$

Incremental radiation exposure $(\Delta \mathrm{RE})$

$$
=\text { Radiation } \text { doses }_{\text {index test }}-\text { Radiation } \operatorname{doses}_{\text {no screening }}(\mu \mathrm{Sv})
$$

"Index test: X-ray following VFA, VFA only, and X-ray only as the Do screening.

Next, we performed univariate and multivariate sensitivity analyses to probe the validity of our model. In the univariate sensitivity analyses, the parameters of the prevalence and incidence of VFs, efficacy of drugs, diagnostic accuracy of VFA, costs of test and VFs treatment, and radiation doses of VFA were varied, using the various sources, range, and conservative approach (Table 1). Since there was no recommended test interval available in the guidelines [16], multivariate sensitivity analysis was conducted using a cycle length of one year.

Finally, the subgroup analysis of old age was conducted for women aged 70 years and older and all men aged 80 years and older since these age groups are recommended especially for VFA in the guidelines $[16,30]$, for which the input parameters are presented in Table 2.

All the statistical analyses were performed by SAS soft-

\begin{tabular}{|c|c|c|c|c|}
\hline \multirow[t]{2}{*}{ Parameters } & \multicolumn{2}{|l|}{ Value $^{a}$} & \multirow[t]{2}{*}{ Sources } & \multirow[t]{2}{*}{ Note } \\
\hline & Women & Men & & \\
\hline \multicolumn{5}{|l|}{ Cycle length one-year } \\
\hline one-year VF incidence & 0.06 & 0.02 & HIRA & NHI database \\
\hline one-year new VF incidence & 0.11 & 0.11 & [19] & Hospital cohort-NHI database linked data \\
\hline VFs treatment $\cos ^{\mathrm{a}}(€)$ & 1458 & 1509 & HIRA & NHI database \\
\hline \multicolumn{5}{|c|}{ Women aged 70 and older, men aged 80 and older } \\
\hline VF prevalence & 0.43 & 0.46 & [18] & Community-based cohort \\
\hline two-year VF incidence & 0.29 & 0.17 & HIRA & NHI database \\
\hline two-year new VF incidence & 0.32 & 0.32 & [19] & Hospital cohort-NHI database linked data \\
\hline RR of new VF on drug therapy & 0.60 & 0.60 & [33] & Meta-analysis, pooled RR \\
\hline Sensitivity of VFA & 0.88 & 0.88 & [34] & Diagnostic accuracy study for elderly adults \\
\hline Specificity of VFA & 0.99 & 0.99 & {$[34]$} & Diagnostic accuracy study for elderly adults \\
\hline VFs treatment $\operatorname{cost}^{\mathrm{a}}(€)$ & 1513 & 1675 & HIRA & NHI database \\
\hline
\end{tabular}
ware version 9.2 (SAS Institute Inc., Cary, NC, USA).

Table 2 Summary of the input parameters in the model for multivariate sensitivity analysis and subgroup analysis 
The model was estimated using TreeAge Pro 2013 (TreeAge Software, Williamstown, MA).

\section{Results}

Base case analysis

No screening versus do screening for prevalent $V F$

For women aged 50 and over for a 10-year time horizon, the new VF incidence was $54.6 \%$ for No screening, and 23.3\% for Do screening with a two-year interval (calculated as the average incidence of X-ray following VFA, VFA only, and X-ray only strategies: $25.2 \%, 25.2 \%$, and $19.6 \%$, respectively). The expected costs were $€ 967$ higher for Do screening; and the radiation exposure was $1427 \mu \mathrm{Sv}$ per capita for Do screening. For men aged 50 and over it was also associated with lower new VF incidence ( $8.4 \%$ for Do screening vs. $22.5 \%$ for No screening) and higher costs ( $€ 658$ for Do screening vs. $€ 27$ for No screening). Comparing Do screening to identify a prevalent VF to No screening, the new VF incidence decreased by $23.3 \%$ with increased costs of $€ 810$, and radiation exposure of $1422 \mu \mathrm{Sv}$ for both women and men aged 50 and over as the weighted average by the 2013 registration population by gender based on the South Korean Statistical Information Service statistics (Table 3) [29].

\section{Three screening strategies for prevalent VF}

Among the three screening strategies performed every two years (Table 3), the X-ray following VFA and VFA only strategies showed the same clinical effect of reducing the new VF incidence by as much as $29.4 \%$ for women, and $12.5 \%$ for men. The most effective strategy was the X-ray only strategy with a new VF incidence reduction of $35 \%$ for women and $17.5 \%$ for men over a 10 -year period. With regard to the costs, X-ray following VFA strategy was less expensive than the others for both women and men. The second economic option was X-ray only strategy, then VFA only strategy ( $\Delta \mathrm{C}$ of $€ 821$, $€ 938$, and $€ 1142$ for women; $€ 477, € 515$, and $€ 899$ for

Table 3 Results of the base case analysis and multivariate sensitivity analysis for the diagnostic strategies during a 10-year period

\begin{tabular}{|c|c|c|c|c|c|c|}
\hline Category & Diagnostic strategies & Effectiveness (\%) & $\Delta \mathrm{E}^{\mathrm{a}}(\%)$ & Costs $(€)$ & $\Delta C^{\mathrm{b}}(€)$ & $\Delta \mathrm{RE}^{\mathrm{C}}(\mu \mathrm{Sv})$ \\
\hline \multicolumn{7}{|l|}{ Women } \\
\hline \multirow[t]{5}{*}{ Base case } & No screening & 54.6 & & 60 & & \\
\hline & Do screening ${ }^{e}$ & 23.3 & -31.3 & 1027 & 967 & 1427 \\
\hline & $X$-ray following VFA & 25.2 & -29.4 & 881 & 821 & 747 \\
\hline & VFA & 25.2 & -29.4 & 1202 & 1142 & 141 \\
\hline & X-ray & 19.6 & -35.0 & 998 & 938 & 3394 \\
\hline \multirow[t]{5}{*}{ Multivariate sensitivity $(\mathrm{Cl}=1$ year $)$} & No screening & 54.6 & & 60 & & \\
\hline & Do screening ${ }^{e}$ & 23.2 & -31.4 & 1102 & 1042 & 2455 \\
\hline & $X$-ray following VFA & 24.8 & -29.7 & 862 & 802 & 996 \\
\hline & VFA & 24.8 & -29.7 & 1418 & 1358 & 254 \\
\hline & X-ray & 19.9 & -34.7 & 1025 & 966 & 6115 \\
\hline \multicolumn{7}{|l|}{ Men } \\
\hline \multirow[t]{5}{*}{ Base case } & No screening & 22.5 & & 27 & & \\
\hline & Do screening ${ }^{e}$ & 8.4 & -14.2 & 658 & 630 & 1416 \\
\hline & $X$-ray following VFA & 10.1 & -12.5 & 504 & 477 & 556 \\
\hline & VFA & 10.1 & -12.5 & 927 & 899 & 147 \\
\hline & X-ray & 5.0 & -17.5 & 542 & 515 & 3545 \\
\hline \multirow[t]{5}{*}{ Multivariate sensitivity $(\mathrm{Cl}=1$ year $)$} & No screening & 54.6 & & 60 & & \\
\hline & Do screening ${ }^{e}$ & 8.3 & -14.2 & 734 & 707 & 2526 \\
\hline & $X$-ray following VFA & 10.1 & -12.4 & 498 & 471 & 828 \\
\hline & VFA & 10.1 & -12.4 & 1143 & 1116 & 267 \\
\hline & X-ray & 4.8 & -17.7 & 560 & 533 & 6483 \\
\hline Total $^{d}$ & Do screening ${ }^{e}$ & 16.4 & -23.3 & 854 & 810 & 1422 \\
\hline
\end{tabular}

VFA vertebral fracture assessment, $\mathrm{Cl}$ Cycle length

${ }^{\mathrm{a}} \Delta \mathrm{E}$ (Incremental effectiveness, \%) $=$ Effect $_{\text {index test }}-$ Effect $_{\text {no screening }}$ in new VFs incident

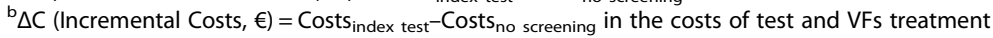

${ }^{c} \triangle \mathrm{RE}$ (Incremental radiation exposure, $\mu \mathrm{Sv}$ ) $=$ Radiation doses index test $^{- \text {Radiation doses }}$ no screening; Radiation doses no screening was assumed to be ' $0 \mu \mathrm{Sv}^{\prime}$ '

${ }^{d}$ In the base case, the weighted average by the registration population by gender (female $=8,649,974$ people; male $=7,590,057$ people) based on Statistics

${ }^{e}$ Do screening presents the average expected values of X-ray following VFA, VFA only, and X-ray only 
men per capita, respectively). Also, the 10-year radiation doses in the X-ray only strategy was from 2647 to $2989 \mu \mathrm{Sv}$ and 3253 to $3398 \mu \mathrm{Sv}$ higher than in the X-ray following VFA or VFA only strategies for both women and men.

\section{Sensitivity analysis}

The results of the univariate sensitivity analysis compared with the base case analysis are shown in Fig. 2. The input parameters of the sensitivity analysis are given in Table 1. The decrease of VF prevalence indicates that not only was the new VF incidence lower, by $1.7 \%$ to $6.9 \%$, but the expected cost was reduced by $€ 70$ to $€ 112$ in all the screening strategies for both women and men. A similar pattern was found for VF incidence, as reduced effectiveness and cost resulted from an increase in VF incidence. Even though these parameters made great changes in effectiveness and cost, the relative rankings among the strategies did not change. In addition, when the sensitivity and specificity of VFA were reduced, the costs of the strategies that included VFA changed.
However, the relative rankings of the strategies were maintained.

The multivariate sensitivity analysis examined the influence of a one-year cycle length compared to the base case analysis of a cycle length of two years during a 10-year period (Table 3). In particular, the X-ray following VFA strategy performed every year for women was beneficial as it was associated with an effect increase in terms of new VF incidence reduction, cost savings, and a slight increase in radiation dose, whereas the X-ray only produced the opposite effect of the X-ray following VFA strategy. The results of the X-ray following VFA strategy for men were similar regardless of the cycle length and the X-ray only strategy of every year increased the effectiveness, cost, and radiation dose. On average, the effectiveness of Do screening on the reduction of new VF incidence was almost identical between the one- and two -year screen intervals. However, the expected cost (about $€ 80$ in women and men) and the radiation exposure (about $1000-1100 \mu \mathrm{Sv}$ in women and men) were slightly increased in the one-year cycle length.

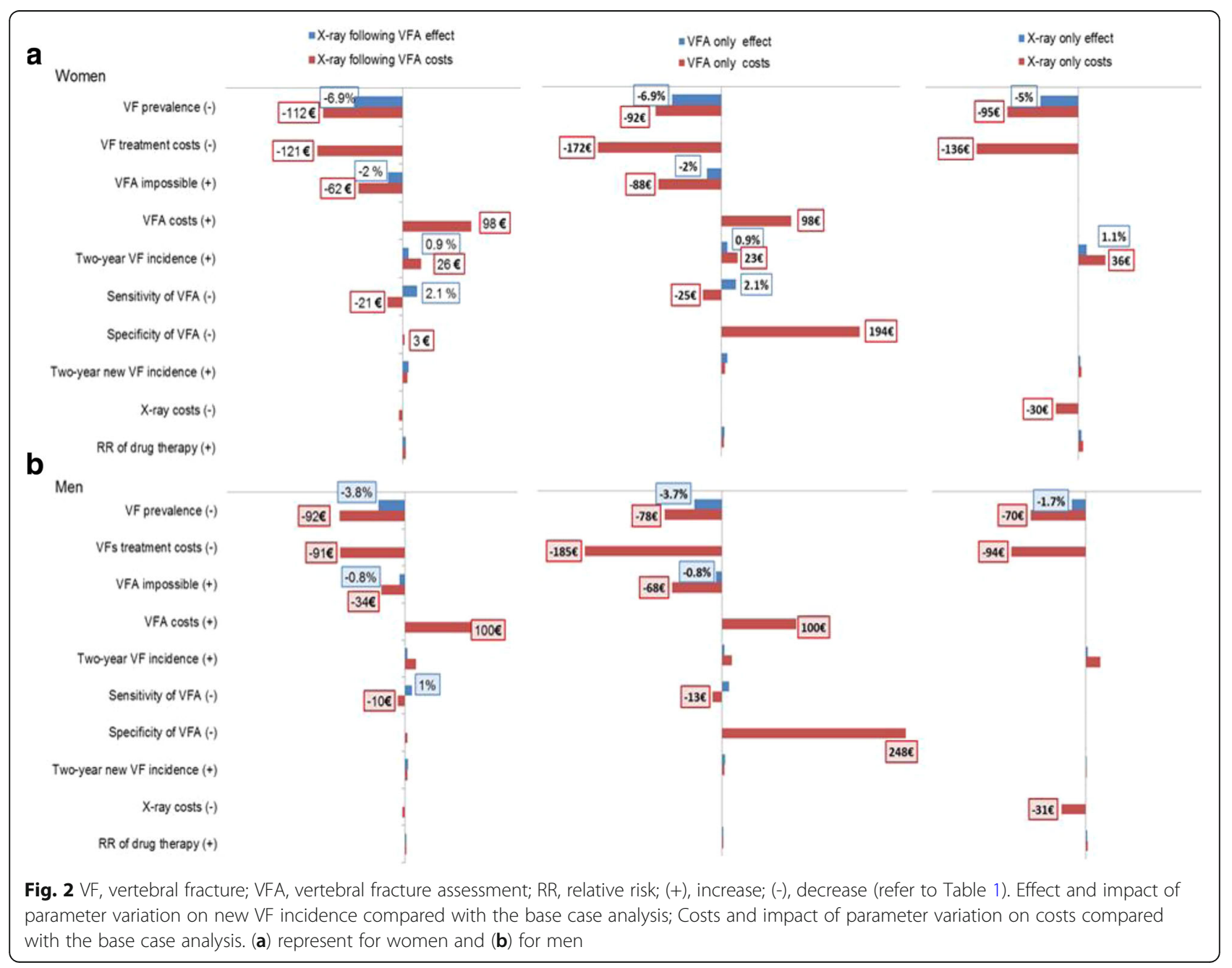




\section{Subgroup analysis}

Figure 3 shows the results from the subgroup analysis for old age people; women aged 70 and older and men aged 80 and older. The preventive effect of Do screening on new VFs was $41.0 \%$ for women and $32.8 \%$ for men compared with No screening. The expected costs were $€ 1602$ per woman aged 70 and over, and $€ 1429$ per man aged 80 and over. The radiation exposure for the old age women and men was comparable with the base case results. Among the three strategies, the overall expected cost of X-ray only strategy was the highest in the subgroup for old people whereas the cost of VFA only strategy was the highest in the base case analysis (Data not shown).

\section{Discussion}

This study demonstrated that doing screening strategies for prevalent VFs has a high preventive effect on reducing new VF incidence for women and men aged 50 years and older compared to a No screening strategy. A cost-effective option was X-ray following VFA strategy, considering that the radiation exposure in $\mathrm{X}$-ray only strategy was much higher than the X-ray following VFA or VFA only strategies.

For a change of two years into the one-year screening interval, the average effects of the three screening strategies for prevalent VF on reducing new VF incidence were almost identical, but the X-ray following VFA strategy for women was especially beneficial resulting in a reduction of the incidence of new VFs, cost savings, and relatively low levels of radiation dose. On average, the clinical effect of incident VF reduction was more than two times in women than in men, more in old people aged 70 and over than in people aged 50 and over, and its effect on old people was increased more in men than in women.

In clinical practice, the X-ray, the gold standard tool for detecting VF, is not routinely performed in the clinical evaluation of people at risk of future fractures. In our study, considering the highest radiation exposure and the second highest cost, a routine X-ray screening strategy might be inferior to the X-ray following VFA. Given that the worldwide average effective dose from natural background radiation was reported to be $2.4 \mathrm{mSv}$ per year [12], the potential risk to an individual might be small because the annual radiation doses of the $\mathrm{X}$-ray strategy in our study had a much lower dose at $0.35 \mathrm{mSv}$. However, cyclical use could have a psychological impact on the compliance of people who are eligible for routine screening for VF.

On the other hand, VFA had the lowest radiation dose and a high preventive effect of new VFs. However, we should carefully consider whether to replace the X-ray with VFA because performing the VFA has a risk of misdiagnosis caused by false negative rates of about $20 \%$ [10]; the costs of VFA are increased with the additional costs of patients receiving unnecessary treatment with a false-positive result. Moreover, even if most osteoporotic VFs occur between T7 and L3, the poor image quality of the upper thoracic vertebrae superior to T7 is a major

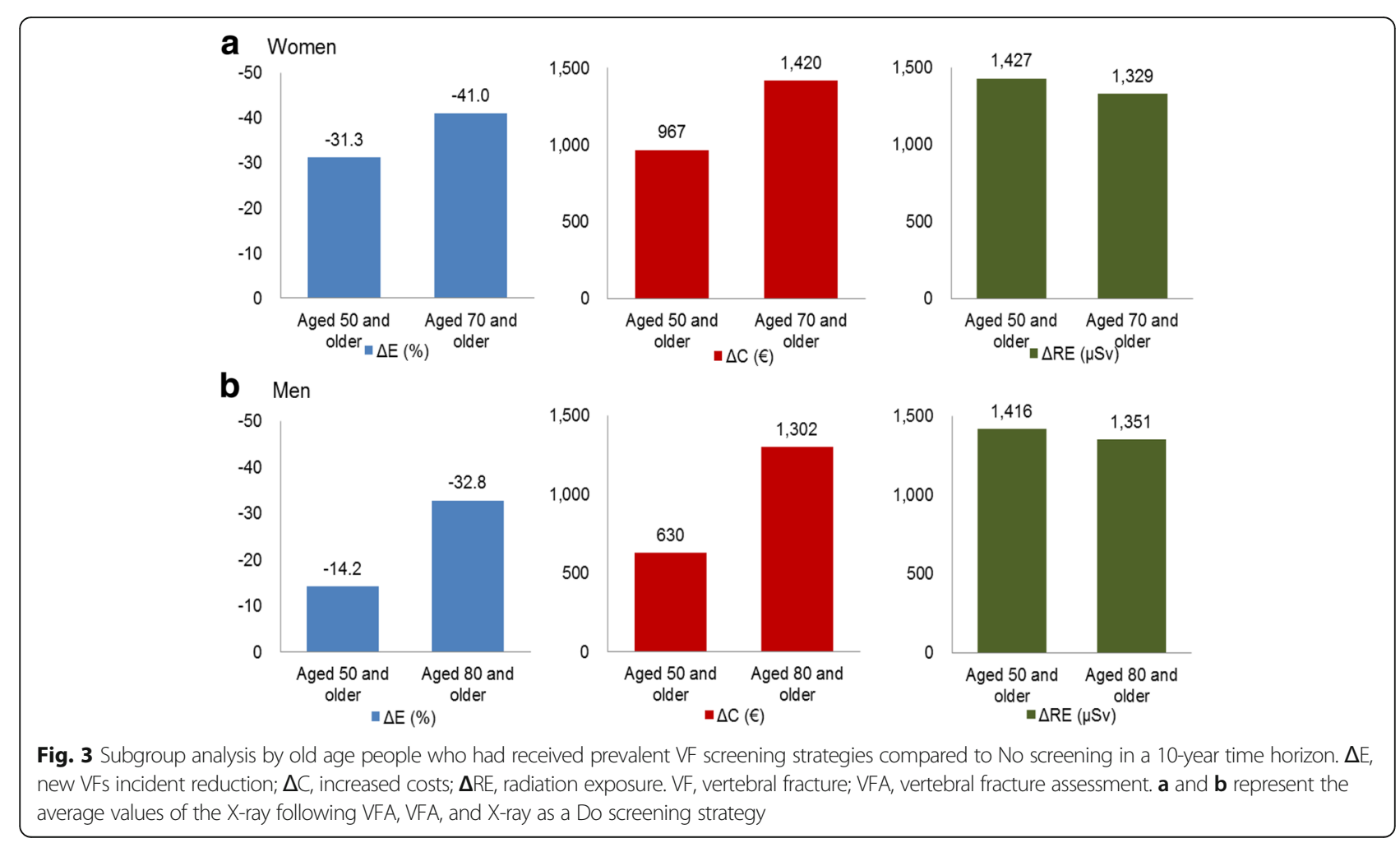


limitation of VFA [11]. Thus our model applied the unreadable probability of VFA, and additional confirmatory imaging (e.g. X-ray) should be considered.

The X-ray following VFA strategy can overcome these problems of VFA with the lowest cost, lower radiation dose than X-ray, and high effect of reducing the new VF. In addition, it can assess VFs at the same time as BMD assessment in contrast to X-ray, which may need referral to another facility [8].

Our study has some limitations. First, since there were no reliable data about adherence to screening and osteoporosis medication, we assumed $100 \%$ adherence for screening as well as medication use. Therefore, this assumption probably overstates the clinical effectiveness of this study. In addition, the use of anti-osteoporotic agents based on BMD values was not considered, since it would be equally applicable to all the patients. Modeling that included information on BMD values in the subject population would be very complex, but it would be possible to perform such additional modeling if real world data from observational studies were included. Second, as we assume that the costs of the VFA test would be half of the $\mathrm{X}$-ray as in the U.S., it should be updated for costs after pricing in each countries. Third, our analysis did not consider patient outcome or health-related quality of life (HRQoL). However, this study has great strength that it revealed the benefits and harm of X-ray following VFA, VFA only, and X- ray only strategies, as a population screening tool. Moreover, we used accurate data on prevalence, incidence and cost using real world data from the $\mathrm{NHI}$ claims database to obtain a more accurate result. Although the new DXA devices such as iDXA are not widely used in the clinical field, the results of this study would be different if we used such a device because of its high sensitivity and specificity [31].

\section{Conclusion}

We suggest that routine screening for VF every one to two years is justified in all populations aged 50 years and older. In particular, an X-ray following VFA strategy can be a relevant option for prevalent VF detection and new VF prevention. Further studies of both HRQoL and cost-utility analysis are needed to promote informed decision making.

\section{Abbreviations}

BMD: Bone mineral density; DXA: Dual energy X-ray absorptiometry;

HIRA: Health insurance review and assessment service; HRQoL: Health-related quality of life; NHI: National Health Insurance; RR: Relative risk; VF: Vertebral fracture; VFA: Vertebral fracture assessment; $X$-ray: Spine radiography

\section{Acknowledgments}

None.

\section{Funding}

This study was completed as part of the health technology assessment project (no. NA-2013-007) funded by the National Evidence-based Healthcare Collaborating Agency in South Korea.

\section{Availability of data and materials}

The datasets used and analyzed during the current study are available from the corresponding author on reasonable request.

\section{Authors' contributions}

SHO, YEL, and YKL performed data correction and analysis. SHO, DK, YEL, DYK, YKL, JHL, SCB, YYC, JP, JA, and YKS contributed to the conception and design of the study. SHO, DK, JA, and YKS involved in drafting the manuscript and revising it critically for important intellectual content. All authors read and approved the final manuscript.

\section{Ethics approval and consent to participate}

Ethics approval for the study design was obtained from the Institutional Ethics Review Committee of the National Evidence-based Healthcare Collaborating Agency in South Korea. Consent to participate was not needed, since this manuscript does not involve any animal or human data or tissue.

Consent for publication

Not applicable.

\section{Competing interests}

YKS reports grants from Pfizer and Eisai. SHO, DK, YEL, DYK, YKL, JHL, SCB, YYC, JHP, JA declare that they have no competing interests.

\section{Publisher's Note}

Springer Nature remains neutral with regard to jurisdictional claims in published maps and institutional affiliations.

\section{Author details}

${ }^{1}$ National Evidence-based Healthcare Collaborating Agency, Seoul, Republic of Korea. ${ }^{2}$ Social and Administrative Pharmacy, College of Pharmacy, Yonsei University, Incheon, Republic of Korea. ${ }^{3}$ Department of Rheumatology, Hanyang University Hospital for Rheumatic Diseases, 222-1 wangsimni-ro, Seoundong-gu, Seoul 133-792, Republic of Korea. ${ }^{4}$ Department of Biostatistics and Epidemiology, Graduate School of Public Health, Seoul National University, Seoul, Republic of Korea. ${ }^{5}$ Department of Nuclear Medicine, Kyung Hee University Hospital, Seoul, Republic of Korea. ${ }^{6}$ Department of Rheumatology, Inje University Ilsan Paik Hospital, Goyang, Republic of Korea. ${ }^{7}$ Department of Nuclear Medicine, Hanyang University Hospital, Seoul, Republic of Korea. ${ }^{8}$ WHO Collaborating Centre for Pharmaceutical Policy and Regulation, Department of Pharmaceutical Science, Utrecht University, Utrecht, Netherlands. ${ }^{9}$ Department of Health Convergence, Ewha Womans University, 52 Ewhayeodae-gil, Seodaemun-gu, Seoul 03760, Republic of Korea.

Received: 10 July 2017 Accepted: 30 January 2018 Published online: 12 February 2018

References

1. Kanis JA, Johnell $O$, De Laet $C$, et al. A meta-analysis of previous fracture and subsequent fracture risk. Bone. 2004;35:375-82.

2. Black DM, Arden NK, Palermo L, Pearson J, Cummings SR. Prevalent vertebral deformities predict hip fractures and new vertebral deformities but not wrist fractures. Study of osteoporotic fractures research group. J Bone Miner Res. 1999;14:821-8.

3. Jang $S$, Park C, Jang $S$, et al. Medical service utilization with osteoporosis. Endocrinol Metab DE. 2010;25:326-39.

4. Fink HA, Milavetz DL, Palermo L, et al. What proportion of incident radiographic vertebral deformities is clinically diagnosed and vice versa? J Bone Miner Res. 2005;20:1216-22.

5. Ensrud KE, Schousboe JT. Clinical practice. Vertebral fractures. N Engl J Med. 2011;364:1634-42

6. Genant HK, Li J, Wu CY, Shepherd JA. Vertebral fractures in osteoporosis: a new method for clinical assessment. J Clin Densitom. 2000;3:281-90.

7. Lindsay R, Silverman SL, Cooper C, et al. Risk of new vertebral fracture in the year following a fracture. JAMA. 2001;285:320-3.

8. Lewiecki EM, Laster AJ. Clinical review: clinical applications of vertebral fracture assessment by dual-energy x-ray absorptiometry. J Clin Endocrinol Metab. 2006;91:4215-22.

9. Schousboe JT, Vokes T, Broy SB, et al. Vertebral fracture assessment: the 2007 ISCD official positions. J Clin Densitom. 2008;11:92-108. 
10. Cosman F, de Beur SJ, LeBoff MS, et al. Clinician's guide to prevention and treatment of osteoporosis. Osteoporos Int. 2014;25:2359-81.

11. Duboeuf F, Bauer DC, Chapurlat RD, Dinten JM, Delmas P. Assessment of vertebral fracture using densitometric morphometry. J Clin Densitom. 2005;8:362-8.

12. Damilakis J, Adams JE, Guglielmi G, Link TM. Radiation exposure in X-ray-based imaging techniques used in osteoporosis. Eur Radiol. 2010;20:2707-14.

13. Lee $\mathrm{JH}$, Lee $\mathrm{YK}$, Oh SH, et al. A systematic review of diagnostic accuracy of vertebral fracture assessment (VFA) in postmenopausal women and elderly men. Osteoporos Int. 2016;27:1691-9.

14. Schousboe JT, Ensrud KE, Nyman JA, Kane RL, Melton LJ 3rd. Costeffectiveness of vertebral fracture assessment to detect prevalent vertebral deformity and select postmenopausal women with a femoral neck Tscore $>-2.5$ for alendronate therapy: a modeling study. J Clin Densitom. 2006;9:133-43.

15. Gray A. Applied methods of cost-effectiveness analysis in health care. vi ed. New York: Oxford University Press; 2011

16. Watts NB, Lewiecki EM, Miller PD, Baim S. National Osteoporosis Foundation 2008 Clinician's guide to prevention and treatment of osteoporosis and the World Health Organization fracture risk assessment tool (FRAX): what they mean to the bone densitometrist and bone technologist. J Clin Densitom. 2008;11:473-7.

17. Shin CS, Kim MJ, Shim SM, et al. The prevalence and risk factors of vertebral fractures in Korea. J Bone Miner Metab. 2012;30:183-92.

18. Kweon SS, Shin MH, Jeong SK, et al. Cohort profile: the Namwon study and the dong-gu study. Int J Epidemiol. 2014;43:558-67.

19. Ahn J, Hyun MK, Kim Y, et al. A study on the evaluation standards of osteoporosis in Korea. Seoul: National Evidence-based Healthcare Collaborating Agency; 2011.

20. Lee $\mathrm{JH}$, Cho SK, Han M, et al. Validity and role of vertebral fracture assessment in detecting prevalent vertebral fracture in patients with rheumatoid arthritis. Joint Bone Spine. 2014;81:149-53.

21. Kanis JA, Johnell O, Black DM, et al. Effect of raloxifene on the risk of new vertebral fracture in postmenopausal women with osteopenia or osteoporosis: a reanalysis of the multiple outcomes of Raloxifene evaluation trial. Bone. 2003;33:293-300.

22. Sung YK, Ahn J, Oh SH, et al. Diagnostic accuracy of vertebral fracture assessment using DXA and comparison of diagnostic strategy of vertebral fracture. Seoul: National Evidence-based Healthcare Collaborating Agency; 2014.

23. Freemantle N, Cooper C, Diez-Perez A, et al. Results of indirect and mixed treatment comparison of fracture efficacy for osteoporosis treatments: a meta-analysis. Osteoporos Int. 2013;24:209-17.

24. Avenell A, Gillespie WJ, Gillespie LD, O'connell D. Vitamin D and vitamin D analogues for preventing fractures associated with involutional and postmenopausal osteoporosis. Cochrane Database Syst Rev. 2005;3:CD000227.

25. Sawka AM, Papaioannou A, Adachi JD, et al. Does alendronate reduce the risk of fracture in men? A meta-analysis incorporating prior knowledge of anti-fracture efficacy in women. BMC Musculoskelet Disord. 2005;6:39.

26. Zhong ZM, Chen JT. Anti-fracture efficacy of risedronic acid in men: a metaanalysis of randomized controlled trials. Clin Drug Investig. 2009;29:349-57.

27. Laster AJ, Lewiecki EM. Vertebral fracture assessment by dual-energy X-ray absorptiometry: insurance coverage issues in the United States. A white paper of the International Society for Clinical Densitometry. J Clin Densitom. 2007; 10:227-38.

28. HIRA. A study on economic evaluation guideline. Seoul: Health Insurance Review and Assessment Service; 2012.

29. Statistics. Korean statistical information service (KOSIS). In: Consumer price index in healthcare; 2011.

30. Schousboe JT, Shepherd JA, Bilezikian JP, Baim S. Executive summary of the 2013 International Society for Clinical Densitometry Position Development Conference on bone densitometry. J Clin Densitom. 2013;16:455-66.

31. Hind K, Cooper W, Oldroyd B, Davies A, Rhodes L. A cross-calibration study of the GE-lunar iDXA and prodigy for the assessment of lumbar spine and total hip bone parameters via three statistical methods. J Clin Densitom. 2015;18:86-92

32. Shin C, Jo N, Kim Y, et al. Study of an osteoporosis management program in Korea. Seoul: Seoul National Univeristy; 2007.
33. Inderjeeth CA, Foo AC, Lai MM, Glendenning P. Efficacy and safety of pharmacological agents in managing osteoporosis in the old old: review of the evidence. Bone. 2009:44:744-51.

34. Schousboe JT, Debold CR. Reliability and accuracy of vertebral fracture assessment with densitometry compared to radiography in clinical practice. Osteoporos Int. 2006:17:281-9.

\section{Submit your next manuscript to BioMed Central and we will help you at every step:}

- We accept pre-submission inquiries

- Our selector tool helps you to find the most relevant journal

- We provide round the clock customer support

- Convenient online submission

- Thorough peer review

- Inclusion in PubMed and all major indexing services

- Maximum visibility for your research

Submit your manuscript at www.biomedcentral.com/submit

) Biomed Central 